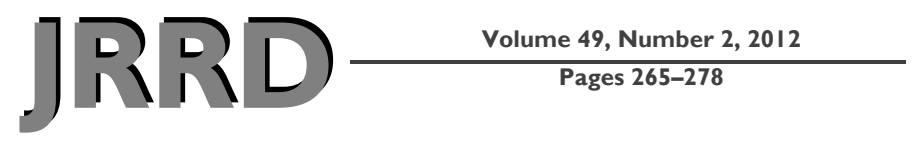

\title{
Exploratory study of perceived quality of life with implanted standing neuroprostheses
}

\author{
Loretta M. Rohde, PT, DPT; ${ }^{{ }^{*}}$ Bette R. Bonder, PhD, OTR/L; ${ }^{2}$ Ronald J. Triolo, PhD ${ }^{1,3}$ \\ ${ }^{1}$ Louis Stokes Cleveland Department of Veterans Affairs Medical Center, Cleveland, OH; and Department of Ortho- \\ paedics, MetroHealth Medical Center, Cleveland, $\mathrm{OH} ;{ }^{2}$ College of Sciences and Health Professions, Cleveland State \\ University, Cleveland, $\mathrm{OH} ;{ }^{3}$ Departments of Orthopaedics and Biomedical Engineering, Case Western Reserve \\ University, Cleveland, $\mathrm{OH}$
}

\begin{abstract}
Individuals with spinal cord injury (SCI) need options for negotiating architectural barriers, completing essential transfers, and accessing items on high shelves or in cupboards that cannot be reached from the wheelchair or safely managed with reachers. Case Western Reserve University (CWRU) and the Department of Veterans Affairs (VA) have developed an assistive technology device to assist individuals with SCI to stand and transfer. The 8-channel implanted CWRU-VA system enables persons with SCI to exercise, stand, and maneuver in the vicinity of their wheelchairs. Interventions that decrease barriers to mobility and participation can have a significant effect on an individual's perceived quality of life (QOL). This study uses a qualitative research methodology comprised of a series of semistructured interviews to determine the effects on perceived QOL of an implanted 8-channel functional electrical stimulation (FES) system for standing after SCI. The results reveal that individuals with SCI currently using an implanted FES standing system perceived significant improvements in QOL related to the neuroprosthesis. Implanted neuroprostheses for standing have the potential to improve QOL for veterans living with SCI.
\end{abstract}

Clinical Trial Registration: ClinicalTrials.gov; NCT00004445, "Study of an implantable functional neuromuscular stimulation system for patients with spinal cord injuries";

http://www.clinicaltrials.gov.

Key words: Department of Veterans Affairs, functional electrical stimulation, mobility, neuroprosthesis, paralysis, qualitative, quality of life, rehabilitation, spinal cord injury, standing.

\section{INTRODUCTION}

Spinal cord injury (SCI) can have devastating effects on an individual's ability to participate in activities that are typical of an independent and productive lifestyle [1]. Individuals with SCI need options for negotiating architectural barriers, completing essential transfers (such as wheelchair to bed, car, or high surfaces and bathroom transfers), and accessing items on high shelves or in cupboards that cannot be reached from the wheelchair or safely managed with reachers [1]. Neuroprostheses employing functional electrical stimulation (FES) can produce useful movements and provide a means to circumvent environmental barriers and increase an individual's ability to participate in meaningful activities [1-5]. Such

Abbreviations: $\mathrm{ADL}=$ activity of daily living, $\mathrm{AT}=$ assistive technology, ATD = assistive technology device, ATD-PA = Assistive Technology Device Predisposition Assessment, CWRU = Case Western Reserve University, FES = functional electrical stimulation, IRB = institutional review board, $\mathrm{MHMC}=$ MetroHealth Medical Center, PIADS $=$ Psychosocial Impact of Assistive Devices Scale, QOL = quality of life, SCI = spinal cord injury, SIP = Sickness Impact Profile, UTI = urinary tract infection, VA = Department of Veterans Affairs.

*Address all correspondence to Loretta M. Rohde, PT, DPT; Total Rehabilitation Specialists, Inc, 232 Concord Ln, Hinckley, OH 44233; 440-877-1100. Email: iwsowle@gmail.com http://dx.doi.org/10.1682/JRRD.2010.08.0156 
motor system neuroprostheses have been reported to facilitate tasks that were previously difficult or impossible from the wheelchair, increase independence, and improve the health of persons with paralysis $[1,4,6]$. Participants in FES programs that enable them to stand reported that leaving the chair for even short periods of time and interacting with others in a standing position helped them feel less disabled [7-8].

One such motor system neuroprosthesis has been developed and deployed in clinical feasibility studies by Case Western Reserve University (CWRU) and the Department of Veterans Affairs (VA). The CWRU-VA implanted standing neuroprosthesis consists of an 8-channel implanted receiver-stimulator and intramuscular or epimysial stimulating electrodes to excite the motor nerves to activate the paralyzed trunk, hip, and knee extensors [3,9]. Between 1996 and 2007, the neuroprosthesis was implanted in a total of 18 subjects at the Louis Stokes Cleveland VA Medical Center, MetroHealth Medical Center (MHMC) in Cleveland, or collaborating institutions [10-11]. Of the implant recipients, 10 were active in the experimental protocol at the time of this study. Preliminary clinical outcomes of the neuroprosthetic intervention indicate that the system enables persons with low-level motor complete tetraplegia and paraplegia (cervical 6-thoracic 12 injury levels) to exercise, stand, and maneuver in the vicinity of their wheelchairs. The participants use the FES system to exercise their hip, knee, and back extensors in order to build and then maintain the strength and endurance of these muscles to enable them to continue using the system for functional mobility and participation in activities of daily living (ADLs). This 8channel system does not allow for reciprocal stepping. The goal of this 8-channel FES system was to enable participants to stand, exercise, and complete standing pivot transfers.

When an individual's impairments or functional limitations are not curable, maximizing quality of life (QOL) and community participation is the desired goal of research, clinical medicine, and health promotion [1215]. According to Dijkers' meta-analysis of QOL for individuals with SCI, interventions that decrease barriers to participation and improve an individual's perception of his or her health are key components that have a significant effect on QOL [16]. Focus group studies of individuals with SCI show that being able to stand and walk are important priorities [2,17-19], along with being more independent and not relying so heavily on caregivers and attendants for assistance [19]. These studies also report that participants feel it is important to be able to socialize more "normally" with friends [19]. Participation in valued activities such as these, which might be affected by standing neuroprostheses, is an important factor in the perceived QOL for individuals with disability [20]. However, the effects of assistive technologies (ATs) employing FES for standing and exercise on QOL have received relatively little attention.

Studies of the effect of assistive technology devices (ATDs) on QOL are becoming increasingly important in justifying both the need for these new technologies and the necessary time and training required to maximize the benefits of these technologies [21]. Although objective measures of the value and outcomes of the use of AT are important, subjective measures are also essential in order to understand how the consumer perceives the device [22]. In addition, the majority of general purpose instruments for measuring rehabilitation and health outcomes do not have adequate responsiveness to measure the effect of a specific device because only a few of the items apply to functions or domains that are potentially affected by the device [23]. A review and analysis of rehabilitation and health outcome measures showed that 74 percent of instruments either ignored AT or that instruments such as the Functional Independence Measure lowered the score if AT was used [24]. For example, to achieve the high score of 7 (where $1=$ total assistance and 7 = complete independence), an individual must be completely independent without using an ATD. If an individual can complete the task without assistance, but requires the use of an ATD, the score is lowered to a 6 with a rating of modified independence.

Other available assessments, such as the Quebec User Evaluation of Satisfaction with Technology [25], have been designed to evaluate the user's impression of a variety of ATDs. While this and other established and validated instruments are being applied to FES interventions for standing, exercise, and transfers, they tend to focus on the participant's satisfaction with the device and service delivery but do not gather information as to how using the device affects QOL. Instruments such as the Assistive Technology Device Predisposition Assessment (ATD-PA) [26] and the Psychosocial Impact of Assistive Devices Scale (PIADS) [27] were developed to capture consumer's perceptions of functioning, temperament, lifestyle, and impressions of an ATD as well as how the ATD affects QOL. The ATD-PA QOL subset targets achievements in functional areas as indicators of QOL but does not address some of the domains identified by Bergner et al. [28], such 
as finances and spontaneity, as influencing QOL for individuals with SCI regardless of severity of impairment. The PIADS limits QOL assessment to three dimensions (competence, adaptability, and self-esteem) [27] but does not address many of the domains identified by Bergner et al. (physical function, accessibility, physical well-being, work and/or productivity, relationships, social function, finances, spontaneity, and stigma) [28]. In addition, these instruments limit the user's rating of QOL to a numerical score. The rich and detailed information that can be gained through qualitative research methods would be missed if using strictly quantitative methods.

Similarly, the Sickness Impact Profile (SIP) is used to evaluate the effect of the 8-channel standing system on overall perceptions of health, an important component of QOL. However, the SIP and similar instruments may not be sensitive enough to capture the full spectrum of positive or negative effects of the system on QOL as evidenced by apparent discrepancies between SIP scores and anecdotal reports from system recipients to the investigators and study personnel. The SIP is a health-related QOL measure, so it actually only measures behaviors related to health status [29]. It does not capture all of the types of functional outcomes or QOL effects that are related to the use of AT. A need clearly exists for a different approach to assessing the effect of neuroprosthesis use on QOL.

At present, no consensus exists among the healthcare disciplines as to what constitutes QOL or how it should be measured [30-37]. It is important to gather information from the perspectives of those being evaluated [31]. Exploring the perceptions of system users themselves can provide rich and detailed information that may offer valuable insight into QOL and be useful in developing future programs and providing rehabilitation services [16,38]. Although qualitative assessments require a significant time investment to gather and interpret the data, the information gained from the use of qualitative measures can be quite valuable.

In order to appreciate QOL from the perspectives of the individuals living with SCI, we must identify the premise on which they base their evaluations of QOL [28]. Based on a review of the literature pertaining to SCI, the domains influencing QOL identified by these individuals are similar to those reported by the general population. The following domains influenced QOL for individuals with SCI regardless of impairment severity: independence, physical function, accessibility, physical well-being, work and/or productivity, emotional well-being, relationships, social function, finances, spontaneity, and stigma [39].

The purpose of this article is to determine whether the use of the CWRU-VA implanted 8-channel standing and transfer neuroprosthesis improved the QOL for individuals with SCI. We defined QOL for this study as the participant's perception of satisfaction with his or her current circumstances or condition in the domains of health, independence, physical function, accessibility, emotional well-being, social and/or recreational function, ability to work, and finances.

\section{METHODS}

We developed a qualitative questionnaire based on the domains that influenced QOL for individuals with SCI as documented in the literature (Figure 1) [39]. We invited all individuals participating in the "Functional paraplegic walking with electrical stimulation" research study at MHMC to participate. The inclusion criteria for the perceived QOL study were as follows: >18 years old, recipient of an implanted neuroprosthesis for standing and transfers, absence of cognitive deficit, and available by telephone. We sent an introductory letter and a copy of the informed consent form to all potential participants. We made a follow-up telephone call to determine their willingness to participate and schedule a convenient time for the interview. We informed participants of the purpose of the study and assured them that their participation was voluntary. We also informed them that their responses would remain confidential in that the results would be presented for the group as a whole.

Two individuals fluent in both Spanish and English translated the informed consent, Health Insurance Portability and Accountability Act authorization, and qualitative questionnaire into Spanish. One individual translated them from English to Spanish and the second individual translated them from Spanish to English. A third individual then compared the translated English version to the original to ensure translation accuracy.

A small pilot study provided an opportunity to assess the effectiveness of the questionnaire and interview process. An interview with participant 1 confirmed that no revisions to the questionnaire were indicated. Only one individual was interviewed during the pilot study because of the small number of available individuals who have received the 8-channel implanted neuroprosthesis. 
1. What does the phrase quality of life mean to you?

2. What things are important to your quality of life?

3. How does FES affect these things?

4. Has the use of FES improved your quality of life? If so, how?

5. Has the use of FES negatively affected your quality of life? If so, how?

6. Has the implanted FES system enabled you to go places or do things that you could not do before? What?

7. Has the implant decreased the amount of help you need to perform certain tasks? Which ones?

8. How would you describe your experience with this research study to a potential participant who is deciding whether or not to get the implant?

9. Do you consider your participation in this research study to be worthwhile? Why or why not?

10. What are the difficulties you have encountered during your participation in this study?

11. What benefits do you receive from using the FES system?

12. Have there been changes in your overall health since receiving the implanted FES system, such as: decreased frequency of urinary tract infections, improvement in skin condition related to pressure sores, decreased spasms, etc.?

13. Has the system enabled you to return to work or altered your work abilities? If so, has the standing system affected your financial status?

14. Since receiving the implanted system, do you get out and socialize more or less frequently or about the same as before?

15. Do you feel that using the system has affected your overall emotional well-being?

16. How has your life changed since FES?

17. Is there anything else I should have asked?

Figure 1.

Questions for semi-structured interviews. FES = functional electrical stimulation.

Prior to each interview, we thoroughly explained the procedures to each participant and verbally obtained informed consent. Then, we collected data via telephone individually using a semi-structured interview format with open-ended questions with each participant. The semistructured interview format allows the interviewer to probe and explore within predetermined inquiry areas [40-41]. We audiotaped all interviews, beginning with the verbal informed consent. Interviews lasted approximately 40 to 50 minutes. The primary researcher transcribed each interview verbatim from the audiotapes. An independent party who listened to the audiotapes while reviewing the transcripts then verified them for accuracy. The transcripts comprised the main data for the study. We collected demo- graphic data for all participants who agreed to participate. We used the transcripts and demographic data in the data analysis.

The primary researcher conducted all interviews except one. Because the remaining participant was not fluent in the English language, an individual fluent in both Spanish and English conducted the interview. We trained this individual in the interviewing technique prior to data collection. After conducting the interview, this second interviewer transcribed the responses verbatim and then translated them into English for data analysis. We decided to include this Spanish-speaking participant because of the small pool of participants available. 
We used the strategy of phenomenology, as described in Morse [42], for this study in order to draw out the essence of the participants' experience with the implanted FES system. This approach allows for a sample size as small as six participants as long as saturation is achieved [42]. The total number of individuals having received the FES system at the time of the study was only 12; the sample therefore represented 75 percent of the available population.

This research incorporated the grounded theory approach developed by Strauss and Corbin [43]. This qualitative research method uses a structured set of procedures to inductively derive a theory from the study of a phenomenon [43]. Open coding is the part of data analysis where the data are closely examined in order to name and categorize phenomena [44]. During the open coding process, the data are broken down, examined closely, and evaluated for similarities and differences. Themes are identified and the data are organized based on these themes [44].

Two investigators independently read each transcript repeatedly in order to analyze the data for themes, patterns, similar words, and context. The investigators had different professional backgrounds. One investigator was a physical therapist and the other was an occupational therapist who is a licensed psychologist with doctoral training, so they were unlikely to share the same viewpoints and more likely to challenge each other's assumptions and interpretations.

Each investigator independently organized similar responses into themes. The investigators then met to compare the identified themes. They found differences to be primarily in specific labeling (e.g., self-care as opposed to ADL). Discussing each cluster led the investigators to conclude that those differences were largely the result of different professional terminology, and they reached agreement on a label for each of the 11 themes. We then returned to the transcripts to code responses independently, at which time we categorized specific participant statements based on the 11 themes.

We took several steps to help ensure the merit or rigor of the methods of this qualitative study. By using audiotapes, transcribing the interviews verbatim, and using direct quotes from the interviews in reporting the results, we enhanced truth value. The credibility of the data analysis was enhanced by the fact that several questions pertaining to the same topic elicited consistent responses. Krefting recommends these strategies [45].
Because of the specificity of this study to the 8-channel implanted standing system, generalizability to other FES systems employing different technologies or rehabilitation methodologies was not a goal. The purpose of this article is to explore a particular phenomenon specific to one configuration of a neuroprosthetic intervention in a restricted population. This article points to some important outcomes of a new and promising rehabilitation intervention and contributes to the growing evidence regarding that intervention's value.

Since QOL is a continuum that changes over time, we do not expect that the results will be the same if this population is interviewed again at a later date. Strategies to ensure neutrality included involving an independent expert (an occupational therapist who is a licensed psychologist with doctoral training with previous qualitative research experience) in the coding process and by having all transcripts verified by an independent party who was otherwise not involved in this research study. These methods are consistent with those suggested by Stanton [41].

\section{RESULTS}

Of the 10 participants currently using an 8-channel implanted FES system for standing, exercise, and transfers, 9 agreed to participate in this study. The tenth individual did not respond to the introductory letter and was unable to be reached by telephone. One individual who had received a second 8-channel implant participated in the pilot study of the questionnaire, and data from that pilot are not included in this analysis. Seven men and one woman between the ages of 29 and 50 participated in the study. The Table summarizes demographic and clinical characteristics of the sample.

Participants provided quite varied definitions of QOL, tending to list factors that reflected their individual biases and personal worldview. The most common factors identified by the majority of the participants as influencing QOL were health, independence, environment, family and/or relationships, and work. Other factors mentioned at least once included money, recreation, contentment and/or happiness, sense of self-worth, security, spiritual well-being, mental state, and balance. Overall, we heard 208 positive statements versus 56 negative statements regarding the use of the implanted FES system for standing, exercise, and transfers. 
Table.

Demographic data.

\begin{tabular}{ccccccc}
\hline Participant & Sex & $\begin{array}{c}\text { Age } \\
\text { at Injury } \\
\text { (yr) }\end{array}$ & $\begin{array}{c}\text { Level } \\
\text { of } \\
\text { Injury }\end{array}$ & $\begin{array}{c}\text { Cause } \\
\text { of } \\
\text { Injury }\end{array}$ & $\begin{array}{c}\text { Time from } \\
\text { Injury } \\
\text { to Implant } \\
\text { (mo) }\end{array}$ & $\begin{array}{c}\text { Time } \\
\text { Since } \\
\text { Implant } \\
\text { (mo) }\end{array}$ \\
\hline 2 & M & 24 & $\begin{array}{l}\text { T6-T7 } \\
\text { (complete) }\end{array}$ & MVA & 33 & 51 \\
3 & F & 26 & $\begin{array}{l}\text { C6-C7 } \\
\text { (incomplete) }\end{array}$ & Sports & 20 & 41 \\
4 & M & 45 & $\begin{array}{l}\text { T6 } \\
\text { (complete) }\end{array}$ & Fall & 15 & 40 \\
5 & M & 32 & $\begin{array}{l}\text { C5-C6 } \\
\text { (complete) }\end{array}$ & MVA & 106 & 34 \\
6 & M & 18 & $\begin{array}{l}\text { T5-T6 } \\
\text { (incomplete) }\end{array}$ & MVA & 202 & 32 \\
7 & M & 25 & $\begin{array}{l}\text { T8 } \\
\text { (complete) }\end{array}$ & MVA & 13 & 28 \\
8 & M & 15 & $\begin{array}{l}\text { T5-T6 } \\
\text { (complete) }\end{array}$ & MVA & 200 & 26 \\
9 & M & 18 & $\begin{array}{l}\text { T5-T6 } \\
\text { (complete) }\end{array}$ & MVA & 197 & 15 \\
\hline C = cervical, F = female, M = male, MVA = motor vehicle accident, T = thoracic.
\end{tabular}

\section{Themes}

Initial analysis of the transcripts revealed 11 themes related to how using an 8-channel implanted standing neuroprosthesis affects participants' QOL. Of these, 10 themes are positive: increased QOL, improved health status, decreased spasticity, improved psychological and/or emotional well-being, value and/or worth, increased mobility, increased function in leisure and/or social settings, being more "normal' or "more like others," ease of ADLs and/or decreased need for caregivers, and enhanced ability to work (Figure 2). The eleventh theme, "no quick fix," reflects a cautionary note.

\section{Increased Quality of Life}

Each participant defined QOL based on his or her values and life experience. The following quotes represent the participants' responses to the question "Has the use of FES improved your quality of life? If so, how?” One participant responded that, "It has improved my quality of life by making it easier to provide for me, to take care of me." Another stated, "I am able to stand with the system and move around and also get a good exercise that way, too. So, that helps with the quality of my life mentally and physically." We also asked a follow-up question as to whether using FES had negatively affected the participants' QOL. Only one individual mentioned any negative effects. This individual mentioned that the scars from the

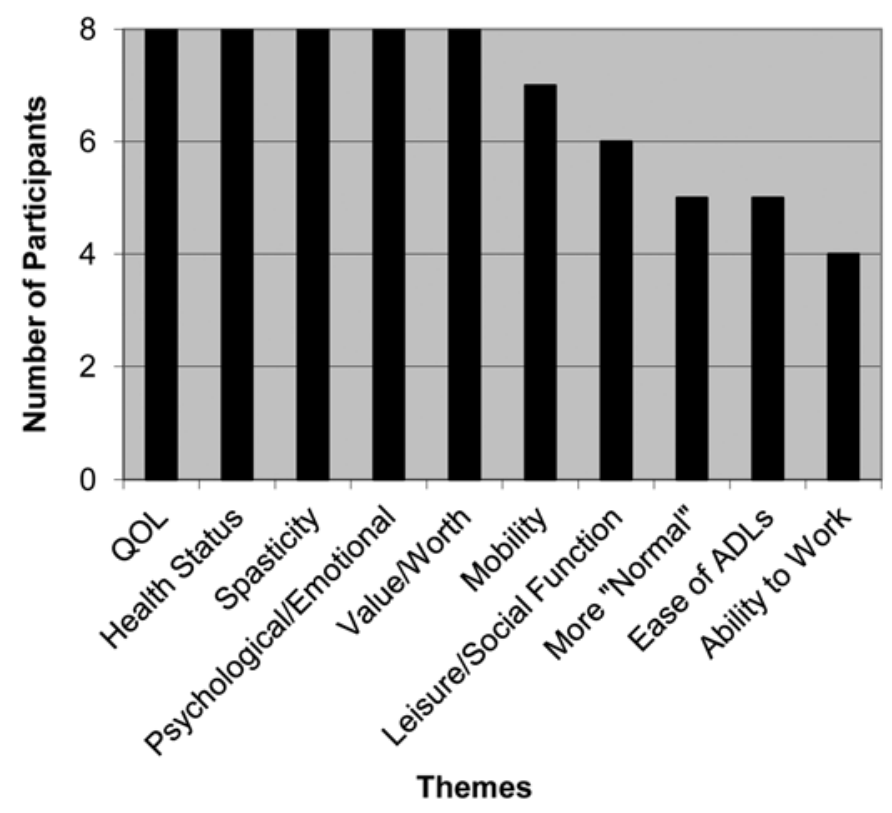

Figure 2.

Themes with improvements attributed to functional electrical stimulation. $A D L=$ activity of daily living, $\mathrm{QOL}=$ quality of life.

implant surgery were a negative effect and that he/she was now more conscious of the risks of infections caused by having a "foreign object within my body."

\section{Improved Health Status}

We based this theme on reports of fewer or less severe symptoms related to secondary conditions associated with SCI. The participants reported overall improvements in their health status when asked the question "Have there been changes in your overall health since receiving the implanted FES system, such as: decreased frequency of urinary tract infections [UTIs], improvement in skin condition related to pressure sores, decreased spasms, etc.?" One participant stated, "The benefit of using your muscles leads to overall better health: cardiovascular, circulation, muscle strengthening, prevents osteoporosis.” Another reported, "I don't have to worry about bedsores or those ulcers near as much.” One individual reported several benefits, including, "It keeps my body mobile, so I'm not just sitting here deteriorating”; "It helps with spasms, circulation and bone density. I don't have atrophy in my legs. I don't get UTIs or pressure sores"; and "You don't get as many complications from just sitting and not doing or moving your body at all.” 


\section{Decreased Spasticity}

We defined spasticity as an increase in muscle tone at rest characterized by increased resistance to passive stretch with exaggerated deep tendon reflexes and clonus [46]. Because so many participants emphasized the effect of the FES system on their spasticity and the importance of having their spasms controlled, we decided to separate it from health status and list it as an individual theme. The following statements represent the diversity of the comments made by participants in response to the questions "What benefits do you receive from using the FES system?" and "Have there been changes in your overall health since receiving the implanted FES system, such as: decreased frequency of urinary tract infections, improvement in skin condition related to pressure sores, decreased spasms, etc.?”

"It helps with spasms."

"I can stand and control my spasticity."

"My spasticity after stimulation was consistently reduced."

"Spasms have gone from nearly being thrown out of the chair to under control."

\section{Improved Psychological/Emotional Well-Being}

This theme includes self-esteem, self-confidence, selfimage, and reduced stress. The following statements represent the participants' responses when asked the following questions: "What benefits do you receive from using the FES system?" and "Do you feel that using the system has affected your overall emotional well-being?” The effect of the implanted FES system on the participants' psychological and emotional well-being is evident in the following statements.

"It takes a lot of stress out of my life."

"I guess just also from an overall sense of selfworth...it kind of gave me a little boost of...my ego.”

"It's just, you know, nice to stand up once in a while."

"First of all, it's given me a good sense of purpose. Second of all, it's given me a tremendous outlook toward the future."

"The psychological benefits are profound."

"It just gives me...confidence that one day, something is going to happen and I'll be ready."

"The psychological, physical, emotional is all, you know, way up on the charts.”
"It's better. I don't get depressed as much."

"I feel happier, never sad, because I feel this is like a way of advancing towards being able to walk."

\section{Value and/or Worth}

Overall, participants reported that they felt that participating in the FES study for standing and transfers was helpful, valuable, and/or worthwhile. The following statements represent their views in response to the questions "How would you describe your experience with this research study to a potential participant who is deciding whether or not to get the implant?" and "Do you consider your participation in this research study to be worthwhile? Why or why not?"

"It is a great system with a lot of benefits."

"It has been a wonderful experience. I am just so glad that I was able to participate into the program."

"There's some work involved in getting the system up and running, but it's well worth it."

"I would recommend it to [anyone with a SCI] if they were willing and wanted to make the commitment and be able to stick through with it."

"I got a cool system that only twelve other people have. Since I am somewhat of a techno-geek, that is pretty cool."

"This is a new technology and I get to provide feedback to improve it."

"This is the best thing available for SCI."

\section{Increased Mobility}

We defined this theme as being able to transfer with less assistance, being able to maneuver into places that are inaccessible by wheelchair, or being able to reach items that are impossible to reach from the wheelchair. The following quotes represent the participants' responses to the questions "Has the implanted FES system enabled you to go places or do things that you could not do before? What?" and "Has the implant decreased the amount of help you need to perform certain tasks? Which ones?" One participant stated, "It allows me to get places that I didn't have easy access to before" and "I move around in places where the wheelchair won't fit. For example, in a hotel where the bathroom door is really small, I use the walker and that's it." Another reported, "It's enabled me to do some things standing that, that I normally wouldn't have been able to do, as far as reaching up high" and "It helps me get up and transfer, go from one chair to another, that I wouldn't be able to do." 


\section{Increased Function in Leisure and/or Social Settings}

We based this theme on the ability to participate in recreational or social activities that were either previously inaccessible or required assistance or the use of adaptive equipment. The majority of participants mentioned this theme when asked "Has the implanted FES system enabled you to go places or do things that you could not do before? What?" and "Since receiving the implanted system, do you get out and socialize more or less frequently or about the same as before?" The importance of increased function in leisure and social settings to QOL related to FES is reflected in the following statements.

"I can talk to a group of people eye to eye."

"I can stand up and hug someone."

"I have more options available to me for social activities."

"I can stand at a concert to see above the crowd."

"For sailing, I just hop on any boat and use the system. Otherwise, I would be limited to only adapted boats or I would have to have someone with me.”

\section{Being More "Normal” or "More Like Others"}

Participants mentioned this theme based on their individual perceptions of normal. Participants made the following statements that demonstrate examples of how FES allowed them to feel more normal in response to the questions "What benefits do you receive from using the FES system?" and "Do you feel that using the system has affected your overall emotional well-being?” One participant stated, "I was able to stand and walk down the aisle for my wedding." Another explained, "When I go to church, I use it so I can stand up and sing, so I feel a little more a part of the regular people.” One participant said, "To be able to be in a picture with my family and friends standing as everybody else is really cool." Another reported, "It felt great to be able to stand without having braces on."

\section{Ease of Activities of Daily Living and/or Decreased Need for Caregivers}

The following quotes represent the participants' responses to the question "Has the implant decreased the amount of help you need to perform certain tasks? Which ones?" One participant stated, "It takes a lot of stress out of my life and out of those who have to care for me." Another reported, "I can be independent in activities that I needed help for before.” One participant explained, "I no longer have to hire an aide to stand or walk with braces. It helps with everyday life things like reaching things off high shelves instead of having to wait for my [spouse] to get home," and before FES, "I could not be left alone for long periods of time.”

\section{Enhanced Ability to Work}

This theme includes paid employment, volunteer work, school, and household duties. Several participants reported using the FES system at work. The following statements represent the participants' reports in response to the questions "Has the implanted FES system enabled you to go places or do things that you could not do before? What?" and "Has the system enabled you to return to work or altered your work abilities? If so, has the standing system affected your financial status?"

"I have been able to be more productive."

"I do use the system at work. I can stand during meetings and to give speeches."

"The system has changed aspects of what I can do. I can spend more time at work... and therefore has increased my economic benefits.”

"I can climb up a truck where the engine is and change any part of it. Without the 'machine' I could climb eventually, but I had to struggle a lot."

"Like I said, it's cut down on my spasm, so I would be able to do a little better work than spazzing out all the time, falling out of my chair and stuff like that."

"It's allowed me to do some things that I would've...let go in the past since I couldn't get to them, such as...driving nails up high or standing to work on a vehicle, like a truck type thing.”

\section{No Quick Fix}

One topic included in this theme is the lack of spontaneity in daily life. Individuals with SCI report that, in general, it takes longer to do things and requires more planning for ADLs. When discussing their experience with the system, all but one of the participants alluded to the fact that there is work involved with being able to use this system and that it takes a commitment in order to be successful. This view is reflected in the following statements, which were made in response to the questions "How would you describe your experience with this research study to a potential participant who is deciding whether or not to get the implant?" and "What are the difficulties that you have encountered during your participation in this study?"

"There is no magic bullet." 
"You have to work if it's worthwhile."

"I would also emphasize the commitment involved. You can't stand immediately after the implant. You have to do a lot of exercise before you can stand. There is no instant gratification."

"The time commitment was difficult. You need to fit the rehab schedule into your work schedule."

"It allows you to do certain things that you can't do, but yet, you're still at least in the early stages, dependent on other people to spot you."

"Putting on the device and all its accessories prior to initiating a stand, transfer or reach, for that matter, takes a lot of time and energy."

"It was tough at the beginning, but now it seems to be a breeze.”

\section{DISCUSSION}

QOL is a multi-dimensional phenomenon that is challenging to describe and measure accurately. Following the recommendations of Haas, we recognize that QOL is most reliably measured by subjective indicators [47]. This is consistent with the viewpoint of Boswell et al. regarding the importance of going beyond rating scales in order to gain an understanding of QOL from the perspective of individuals with SCI [48-49]. Instead of our team of researchers predicting and predetermining what variables are important to our participants and therefore should be measured, we decided to start with a qualitative approach to explore how our participant pool defined QOL and what factors they identified as influencing how they perceive quality in their lives. The themes identified in this study allow us to understand the experiences beyond what can be captured by quantitative measurements. Had we limited our investigation of QOL by using an existing tool such as the ATD-PA or the PIADS, we would have overlooked important insights, such as the effects of the neuroprosthesis on finances and spontaneity, as well as feeling more normal or more like others, having less need for caregivers, decreased spasticity, and the cautionary note of no quick fix. Exploring the perceptions of system users themselves can provide rich and detailed information that may offer valuable insight into QOL and be useful in developing future technology and providing rehabilitation services. The findings from this study highlight the emotional value the participants place on their experience with the FES system. Descrip- tions of the CWRU-VA standing system affecting QOL in the areas of the 11 themes we identified provide a comprehensive image of the participants' experience. These themes are consistent with definitions in the literature regarding characteristics of good QOL [13,50-61] for individuals with SCI.

Participants felt that both the experience of participating in the FES research study and this QOL study were very worthwhile. They reported that using the FES system had an overall positive effect on how they rated their QOL. Their reports described many benefits in multiple domains that influence QOL. These benefits have the potential to minimize some of the secondary conditions associated with SCI (such as spasticity, UTIs, and pressure sores) as well as the related expenses for medical care to treat these conditions. In addition, as a result of increased independence and functional mobility, one individual reported a decreased need for hired assistance. There were also four situations where using the FES system enhanced the participants' ability to work, which improved the participants' financial status. A reduced need for assistance, reduced incidence of secondary medical conditions, and an increased ability to be employed may all be financially beneficial because of potentially decreased expenses for care and increased income.

Work is a complex construct that most likely reflects more than one theme. Work is not limited to the ability to maintain employment. The construct encompasses other themes such as financial status, dignity, self-worth, and psychological and/or emotional issues such as being able to provide for one's family [62-64], especially in cases where the individual was the primary provider before the injury. A closer analysis of the data with respect to the theme of work is beyond the scope of this article; however, it is an important issue that should be addressed separately in a future study.

The FES system can eliminate the heavy lifting required by caregivers during standing pivot transfers. This becomes increasingly important as individuals with SCI and their caregivers age. In situations where individuals require assistance for transfers, the decreased physical assistance required from the caregiver may make the difference between an individual being able to remain at home versus being placed in a long-term care facility [11].

One of the themes mentioned by several participants was that the FES system was no quick fix. They alluded to the fact that there is work involved with learning to use this system and that it takes a commitment in order to be 
successful. One participant also mentioned that putting on the device prior to initiating a stand or transfer takes a lot of time and energy. If the user of the FES system does not believe that the benefits outweigh the inconveniences, the device will likely be abandoned. As with other interventions, many people are looking for a "quick fix" where they can take a pill or push a button and achieve the desired result (e.g., to lose weight or tone muscles). Although we do educate our participants regarding reasonable expectations at every step of the process, many still expect that they will see impressive results quickly. As one participant mentioned during an interview, "I was going to be the one that did better and went further, faster than everyone else." As advances in technology are made, many of the areas that the participants identify as causing decreases in spontaneity can be addressed, e.g., moving to wireless systems instead of having to position and secure a coil to control the implant.

All eight of the participants reported that they perceived that using the implanted FES system improved their QOL. As indicated in the findings, positive assessments greatly outweighed negative ones. The primary negative assessments had to do with the challenges of the adjustment period and the lack of spontaneity imposed by use of the FES system. Clearly, enhanced abilities and the sense of being more normal were considered adequate reward for the system's difficulties.

\section{Limitations}

One limitation of this study is the small number of participants. This reflects the small number of individuals who have received an implanted FES system for standing, exercise, and transfers. Although small, the sample is a large representation of the pool of possible participants. Because the data analysis showed that saturation was reached (by the end of the data analysis, the responses from participants were repetitive and no longer provided new insights into the experience) [65], the sample size appears to have been sufficient. Another limitation is that the participants were quite varied in level of injury, functional ability, age, time since injury, social situation, economic situation, and employment status. Further, the participants were not representative of the 4:1 male to female ratio of those living with SCI. Only one woman was included in the study. The male to female ratio of 7:1 was possibly related to the potential risks of FES during pregnancy since most of the research population is still in the childbearing years.

Another potential limitation is that the primary interviewer was one of the physical therapists involved with the rehabilitation training program that recipients experienced after the FES implant. The researcher's personal experience with this group of participants could be a source of bias in the results of this small-scale study. However, having another investigator who did not know the participants code and interpret the data independently may have mitigated the potential effects of any bias on the results and conclusions.

Using a second interviewer to conduct one interview with a Spanish-speaking participant is a limitation. Although the Spanish-speaking interviewer was trained in the technique, his interviewing style may have differed from the primary interviewer. This interview was transcribed verbatim and then translated from Spanish to English by this second interviewer. To strengthen the credibility of the data, the translation could have then been back-translated into Spanish for thorough comparison to ensure that intended meaning of the responses was not lost in the translation. Although these issues are potential limitations in the methodology employed, the consistency of the responses of the non-English-speaking participant with those obtained from other respondents would seem to indicate that such potential influences were minimal in this study.

\section{Future Research}

Further research is needed in this area. As more individuals receive implanted systems, a larger potential pool of research participants becomes available. This study should be replicated with a larger number of participants. Using the information gathered in this study, it may be possible to identify an existing validated assessment tool that addresses the domains reported as influencing QOL by our participants. The data collected using that quantitative measure can then be enhanced with additional information gathered by qualitative methods. In addition, similar studies using both qualitative and quantitative approaches could be performed with populations using other FES systems, such as surface stimulation or percutaneous FES, to allow for a more diverse pool.

A future study that explores the interaction between functional outcomes and QOL is warranted. Note that in this study, seven out of eight participants reported increased mobility, while only five out of eight and four 
out of eight reported improvements in ADLs and ability to work, respectively. However, all participants reported improved QOL since beginning participation in the FES study for standing and transfers.

Further studies, similar to those already published for neuroprostheses for bladder control and hand grasp [6667], are needed to examine the financial cost-benefit issue of motor system neuroprostheses for standing and mobility. An in-depth study of the influence of the FES system on decreasing the need for assistance (which may allow individuals to remain at home and reduce the need for hired help), decreasing the incidence of secondary medical conditions (which may reduce medical expenses), and increasing the ability to work (which may increase income) would be warranted. As the cost of the device decreases, the financial benefits may well outweigh those additional costs.

\section{CONCLUSIONS}

Based on the data collected in this study, we demonstrated that using the CWRU-VA 8-channel implanted neuroprosthesis for exercise, standing, and transfers affected the participants' perceptions of QOL. The domains in which improvement was most often reported include improved health status (including decreased spasticity); improved psychological status and/or emotional well-being (feeling more "normal," decreased stress, increased selfesteem, and increased confidence); increased mobility; better function in recreational and/or social settings; increased independence and/or less need for caregivers; and increased ability to work that, in some cases, led to improved financial status.

\section{ACKNOWLEDGMENTS}

\section{Author Contributions:}

Study concept and design: L. M. Rohde, B. R. Bonder.

Acquisition of data: L. M. Rohde.

Analysis and interpretation of data: L. M. Rohde, B. R. Bonder.

Drafting of manuscript: L. M. Rohde.

Critical revision of manuscript for important intellectual content:

B. R. Bonder, R. J. Triolo.

Statistical analysis: L. M. Rohde, B. R. Bonder.

Obtained funding: R. J. Triolo.

Administrative, technical, or material support: B. R. Bonder, R. J. Triolo. Study supervision: B. R. Bonder, R. J. Triolo.
Financial Disclosures: The authors have declared that no competing interests exist.

Funding/Support: This material was based on work supported by the VA Rehabilitation Research and Development Service (grant B3155R); U.S. Food and Drug Administration, Office of Orphan Product Development (grant FD-R-001244); and the National Institutes of Health Clinical Research Unit at CWRU (grant UL1 RR024989).

Additional Contributions: The authors acknowledge Susan M. Phillips, MEd, for her contribution of verifying the accuracy of the interview transcripts. Dr. Rohde is now with Total Rehabilitation Specialists, Inc, Hinckley, Ohio.

Institutional Review: We obtained institutional review board (IRB) approval from MHMC and Cleveland State University. The IRB approval included the use of a verbal informed consent for this study. Participant Follow-Up: The authors plan to inform participants of the publication of this study.

\section{REFERENCES}

1. Triolo RJ, Bogie K. Lower extremity applications of functional neuromuscular stimulation after spinal cord injury. Top Spinal Cord Inj Rehabil. 1999;5(1):44-65. http://dx.doi.org/10.1310/UXUE-5L1R-WKKV-1RGP

2. Betz RR, Mulcahey MJ. Restoration of function in children with spinal cord injuries and cerebral palsy: Progress, current state and future vision of functional electrical stimulation research at the Shriners Hospitals for Children. Top Spinal Cord Inj Rehabil. 2000;6(Suppl):110-24. http://dx.doi.org/10.1310/TT9K-GYAL-CBPK-CYMN

3. Davis JA Jr, Triolo RJ, Uhlir J, Bieri C, Rohde L, Lissy D, Kukke S. Preliminary performance of a surgically implanted neuroprosthesis for standing and transfers-Where do we stand? J Rehabil Res Dev. 2001;38(6):609-17. [PMID:11767968]

4. Grill WM, Kirsch RF. Neuroprosthetic applications of electrical stimulation. Assist Technol. 2000;12(1):6-20.

[PMID:11067578] http://dx.doi.org/10.1080/10400435.2000.10132006

5. Quintern J. Application of functional electrical stimulation in paraplegic patients. NeuroRehabilitation. 1998;10:205-50. http://dx.doi.org/10.1016/S1053-8135(97)00058-9

6. Agarwal S, Triolo RJ, Kobetic R, Miller M, Bieri C, Kukke S, Rohde L, Davis JA Jr. Long-term user perceptions of an implanted neuroprosthesis for exercise, standing, and transfers after spinal cord injury. J Rehabil Res Dev. 2003;40(3): 241-52. [PMID:14582528]

7. Guest RS, Klose KJ, Needham-Shropshire BM, Jacobs PL. Evaluation of a training program for persons with SCI paraplegia using the Parastep 1 ambulation system: Part 4. Effect on physical self-concept and depression. Arch Phys 
Med Rehabil. 1997;78(8):804-7. [PMID:9344297]

http://dx.doi.org/10.1016/S0003-9993(97)90191-X

8. Kralj A, Bajd T. Functional electrical stimulation: Standing and walking after spinal cord injury. Boca Raton (FL): CRC Press, Inc; 1989. p. 110-22.

9. Davis JA Jr, Triolo RJ, Uhlir JP, Bhadra N, Lissy DA, Nandurkar S, Marsolais EB. Surgical technique for installing an eight-channel neuroprosthesis for standing. Clin Orthop Relat Res. 2001;385(385):237-52. [PMID:11302320] http://dx.doi.org/10.1097/00003086-200104000-00035

10. Forrest GP, Smith TC, Triolo RJ, Gagnon JP, DiRisio D, Miller ME, Murray L, Davis JA, Iqbal A. Energy cost of the Case Western Reserve standing neuroprosthesis. Arch Phys Med Rehabil. 2007;88(8):1074-76. [PMID:17678672] http://dx.doi.org/10.1016/j.apmr.2007.05.011

11. Mushawar VK, Jacobs PL, Normann RA, Triolo RJ, Kleitman N. New functional neuromuscular stimulation approaches to standing and walking. J Neural Eng. 2007;4(3):S181-97. [PMID: 17873417]

12. Hallin P, Sullivan M, Kreuter M. Spinal cord injury and quality of life measures: A review of instrument psychometric quality. Spinal Cord. 2000;38(9):509-23. [PMID:11035471] http://dx.doi.org/10.1038/sj.sc.3101054

13. Schipper H, Clinch JJ, Olweny CL. Quality of life studies: Definitions and conceptual issues. In: Spilker B, editor. Quality of life and pharmacoeconomics in clinical trials. 2nd ed. Philadelphia (PA): Lippincott-Raven Publishers; 1996. p. 11-23.

14. Schipper H, Clinch J, Powell V. Definitions and conceptual issues. In: Spilker B, editor. Quality of life assessments in clinical trials. New York (NY): Raven Press Ltd; 1990. p. 11-24.

15. Magasi SR, Heinemann AW, Whiteneck GG; Quality of Life/Participation Committee. Participation following traumatic spinal cord injury: An evidence-based review for research. J Spinal Cord Med. 2008;31(2):145-56. [PMID:18581661]

16. Dijkers M. Quality of life after spinal cord injury: A meta analysis of the effects of disablement components. Spinal Cord. 1997;35(12):829-40. [PMID:9429262] http://dx.doi.org/10.1038/sj.sc.3100571

17. Brown-Triolo DL, Roach MJ, Nelson K, Triolo RJ. Consumer perspectives on mobility: Implications for neuroprosthesis design. J Rehabil Res Dev. 2002;39(6):659-69. [PMID:17943668]

18. Brown-Triolo DL, Triolo RJ, Roach MJ, Nelson K, Peckham PH. Mobility issues in paraplegia. J Spinal Cord Med. 1999;22(1):29-30.

19. Kilgore KL, Scherer M, Bobblitt R, Dettloff J, Dombrowski DM, Godbold N, Jatich JW, Morris R, Penko JS, Schremp ES, Cash LA. Neuroprosthesis consumers' forum: Consumer priorities for research directions. J Rehabil Res Dev. 2001; 38(6):655-60. [PMID:11767973]

20. Tam S-F. Quality of life: Theory and methodology in rehabilitation. Int J Rehabil Res. 1998;21(4):365-74.

[PMID:9926351]

http://dx.doi.org/10.1097/00004356-199812000-00003

21. Scherer MJ. Outcomes of assistive technology use on quality of life. Disabil Rehabil. 1996;18(9):439-48.

[PMID:8877302]

http://dx.doi.org/10.3109/09638289609165907

22. DeRuyter F. Evaluating outcomes in assistive technology: Do we understand the commitment? Assist Technol. 1995; 7(1):3-16. [PMID:10150748] http://dx.doi.org/10.1080/10400435.1995.10132246

23. Fuhrer MJ. Assistive technology outcomes research: Challenges met and yet unmet. Am J Phys Med Rehabil. 2001; 80(7):528-35. [PMID:11421522] http://dx.doi.org/10.1097/00002060-200107000-00013

24. Rust KL, Smith RO. Assistive technology in the measurement of rehabilitation and health outcomes: A review and analysis of instruments. Am J Phys Med Rehabil. 2005;84(10):780-96. [PMID:16205434]

http://dx.doi.org/10.1097/01.phm.0000179520.34844.0e

25. Demers L, Weiss-Lambrou R, Ska B. Development of the Quebec User Evaluation of Satisfaction with assistive Technology (QUEST). Assist Technol. 1996;8(1):3-13. [PMID:10159726] http://dx.doi.org/10.1080/10400435.1996.10132268

26. Scherer MJ, Sax C, Vanbiervliet A, Cushman LA, Scherer JV. Predictors of assistive technology use: The importance of personal and psychosocial factors. Disabil Rehabil. 2005;27(21):1321-31. [PMID:16298935] http://dx.doi.org/10.1080/09638280500164800

27. Day H, Jutai J. Measuring the psychosocial impact of assistive devices: The PIADS. Can J Rehabil. 1996;9(3):159-68.

28. Bergner M, Bobbitt RA, Carter WB, Gilson BS. The Sickness Impact Profile: Development and final revision of a health status measure. Med Care. 1981;19(8):787-805. [PMID:7278416] http://dx.doi.org/10.1097/00005650-198108000-00001

29. Anderson KL, Burckhardt CS. Conceptualization and measurement of quality of life as an outcome variable for health care intervention and research. J Adv Nurs. 1999; 29(2):298-306. [PMID:10197928] http://dx.doi.org/10.1046/j.1365-2648.1999.00889.x

30. Pain K, Dunn M, Anderson G, Darrah J, Kratochvil M. Quality of life: What does it mean in rehabilitation? J Rehabil. 1998;64(2):5-11.

31. Carr AJ, Gibson B, Robinson PG. Measuring quality of life: Is quality of life determined by expectations or experience? BMJ. 2001;322(7296):1240-43. [PMID:11358783] http://dx.doi.org/10.1136/bmj.322.7296.1240 
32. Ferrans CE, Powers MJ. Quality of life index: Development and psychometric properties. ANS Adv Nurs Sci. 1985;8(1):15-24. [PMID:3933411]

33. Mayers CA. Defining and assessing quality of life. $\mathrm{Br} \mathrm{J}$ Occup Ther. 1995;58(4):146-50.

34. McDaniel RW, Bach CA. Quality of life: A concept analysis. Nurs Res. 1994;3(1):18-22.

35. Mor V, Guadagnoli E. Quality of life measurement: A psychometric tower of Babel. J Clin Epidemiol. 1988;41(11): 1055-58. [PMID:3204415] http://dx.doi.org/10.1016/0895-4356(88)90074-1

36. Stewart AL. Conceptual and methodologic issues in defining quality of life: State of the art. Prog Cardiovasc Nurs. 1992;7(1):3-11.

37. Tate DG, Kalpakjian CZ, Forchheimer MB. Quality of life issues in individuals with spinal cord injury. Arch Phys Med Rehabil. 2002;83(12 Suppl 2):S18-25. [PMID:12474168] http://dx.doi.org/10.1053/apmr.2002.36835

38. Krause JS. Dimensions of subjective well-being after spinal cord injury: An empirical analysis by gender and race/ ethnicity. Arch Phys Med Rehabil. 1998;79(8):900-909. [PMID:9710160] http://dx.doi.org/10.1016/S0003-9993(98)90085-5

39. Manns PJ, Chad KE. Components of quality of life for persons with a quadriplegic and paraplegic spinal cord injury. Qual Health Res. 2001;11(6):795-811. [PMID:11710078] http://dx.doi.org/10.1177/104973201129119541

40. Britten N. Qualitative interviews in medical research. BMJ. 1995;311(6999):251-53. [PMID:7627048] http://dx.doi.org/10.1136/bmj.311.6999.251

41. Stanton S. Client-partner relationships post stroke: Exploring the perspectives of couples. In: Hammell KW, Carpenter C, Dyck I, editors. Using qualitative research. A practical introduction for occupational and physical therapists. New York (NY): Churchill Livingstone; 2000. p. 55.

42. Morse JM. Designing funded qualitative research. In: Denzin NK, Lincoln YS, editors. Handbook of qualitative research. Thousand Oaks (CA): Sage Publications; 1994. p. 220-35.

43. Strauss A, Corbin J. Basics of qualitative research. Grounded theory procedures and techniques. Newbury Park (CA): Sage Publications; 1990. p. 23-24.

44. Strauss A, Corbin J. Basics of qualitative research. Grounded theory procedures and techniques. Newbury Park (CA): Sage Publications; 1990. p. 62.

45. Krefting L. Rigor in qualitative research: The assessment of trustworthiness. Am J Occup Ther. 1991;45(3):214-22. [PMID:2031523]

46. Stedman's medical dictionary. 28th ed. Baltimore (MD): Lippincott Williams \& Wilkins; 2006.

47. Haas BK. A multidisciplinary concept analysis of quality of life. West J Nurs Res. 1999;21(6):728-42. [PMID:11512210] http://dx.doi.org/10.1177/01939459922044153
48. Boswell BB. Exploring quality of life of adults with spinal cord injuries. Percept Mot Skills. 1997;84(3 Pt 2):1149-50. [PMID:9229426]

http://dx.doi.org/10.2466/pms.1997.84.3c.1149

49. Boswell BB, Dawson M, Heininger E. Quality of life as defined by adults with spinal cord injuries. J Rehabil. 1998; 64(1):27-32.

50. Schipper H. Quality of life: Principles of the clinical paradigm. J Psychosoc Oncol. 1990;8(2-3):171-85 http://dx.doi.org/10.1300/J077v08n02_09

51. Zhan L. Quality of life: Conceptual and measurement issues. J Adv Nurs. 1992;17(7):795-800. [PMID:1644975] http://dx.doi.org/10.1111/j.1365-2648.1992.tb02000.x

52. Cella DF. Quality of life: Concepts and definition. J Pain Symptom Manage. 1994;9(3):186-92. [PMID:8014530] http://dx.doi.org/10.1016/0885-3924(94)90129-5

53. Bergner M. Quality of life, health status, and clinical research. Med Care. 1989;27(3 Suppl):S148-56. [PMID:2646487] http://dx.doi.org/10.1097/00005650-198903001-00012

54. WHOQOL Group. The World Health Organization Quality of Life assessment (WHOQOL): Development and general psychometric properties. Soc Sci Med. 1998;46(12):1569-85. [PMID:9672396] http://dx.doi.org/10.1016/S0277-9536(98)00009-4

55. Hoffman LG, Rouse MW, Brin BN. Quality of life: A review. J Am Optom Assoc. 1995;66(5):281-89. [PMID:7629368]

56. Warren L, Wrigley JM, Yoels WC, Fine PR. Factors associated with life satisfaction among a sample of persons with neurotrauma. J Rehabil Res Dev. 1996;33(4):404-8. [PMID:8895135]

57. Raphael D. Defining quality of life: Eleven debates concerning its measurement. In: Renwick R, Brown I, Nagler M, editors. Quality of life in health promotion and rehabilitation. Thousand Oaks (CA): Sage Publications; 1996. p. 159-60.

58. Fuhrer MJ, Rintala DH, Hart KA, Clearman R, Young ME. Relationship of life satisfaction to impairment, disability, and handicap among persons with spinal cord injury living in the community. Arch Phys Med Rehabil. 1992;73(6): 552-57. [PMID:1622304]

59. Lundqvist C, Siösteen A, Sullivan L, Blomstrand C, Lind B, Sullivan M. Spinal cord injuries: A shortened measure of function and mood. Spinal Cord. 1997;35(1):17-21. [PMID:9025214]

http://dx.doi.org/10.1038/sj.sc.3100347

60. Boschen KA. Measuring quality of life of adults with spinal cord injuries: Lessons for developmental disabilities research. J Dev Disabil. 1997;5(1):91-95.

61. Bach CA, McDaniel RW. Quality of life in quadriplegic adults: A focus group study. Rehabil Nurs. 1993;18(6): 364-67,374. [PMID:7938891] 
62. MacDonald-Wilson KL. Work, careers, and disability. In: The professional counselor's desk reference. New York (NY): Springer Publishing Company; 2009. p. 455-65.

63. Baker NA, Jacobs K, Tickle-Degnen L. A methodology for developing evidence about meaning in occupation: Exploring the meaning of working. OTJR. 2003;23(2):57-66.

64. Fabian ES. Occupational choice and the meaning of work. In: The professional counselor's desk reference. New York (NY): Springer Publishing Company; 2009. p. 421-30.

65. DePoy E, Gitlin LN. Gathering information in naturalistic inquiry. In: Introduction to research. Understanding and applying multiple strategies. 2nd ed. St. Louis (MO): Mosby, Inc; 1998. p. 211-34.

66. Creasey GH, Kilgore KL, Brown-Triolo DL, Dahlberg JE, Peckham PH, Keith MW. Reduction of costs of disability using neuroprostheses. Assist Technol. 2000;12(1):67-75. [PMID:11067579]

http://dx.doi.org/10.1080/10400435.2000.10132010
67. Creasey GH, Dahlberg JE. Economic consequences of an implanted neuroprosthesis for bladder and bowel management. Arch Phys Med Rehabil. 2001;82(11):1520-25. [PMID:11689970] http://dx.doi.org/10.1053/apmr.2001.25912

Submitted for publication August 19, 2010. Accepted in revised form July 26, 2011.

This article and any supplementary material should be cited as follows:

Rohde LM, Bonder BR, Triolo RJ. Exploratory study of perceived quality of life with implanted standing neuroprostheses. J Rehabil Res Dev. 2012;49(2):265-78. http://dx.doi.org/10.1682/JRRD.2010.08.0156

\begin{tabular}{|c|c|}
\hline Au subussicns scregened Br. & ef \\
\hline 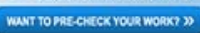 & $\begin{array}{l}\text { CROSSREF. ORG } \\
\text { THE CITATIOH LINKIHG BACKEONE }\end{array}$ \\
\hline
\end{tabular}

